Article

\title{
A Triple-Helix Approach for the Assessment of Hyperloop Potential in Europe
}

\author{
Konstantinos Gkoumas ${ }^{1, *(\mathbb{D})}$ and Michalis Christou ${ }^{2}$ \\ 1 European Commission, Joint Research Centre (JRC), 21027 Ispra, Italy \\ 2 European Commission, Joint Research Centre (JRC), 1049 Brussels, Belgium; michalis.christou@ec.europa.eu \\ * Correspondence: konstantinos.gkoumas@ec.europa.eu; Tel.: +39-03-3278-6041
}

Received: 28 July 2020; Accepted: 22 September 2020; Published: 23 September 2020

check for

updates

\begin{abstract}
Hyperloop is a proposed high-speed surface mode of passenger and freight transport that has gained much visibility in recent years. Since its introduction in modern form in 2013, progress on Hyperloop has been thriving, with several companies involved in research and development of Hyperloop systems and subsystems. Some of them have planned testing tracks in Europe, anticipating what could be the start of commercial routes. Nevertheless, there are concerns that need to be addressed regarding the safety and serviceability performance, and further steps are necessary for the standardization and certification of the system. This study leverages the state of play of Hyperloop development, identifies issues and challenges from a European perspective, and provides policy insights towards testing and commercialization. To this end, it follows a two-tier approach that (i) addresses safety concerns related to the implementation of Hyperloop as a key enabler of the proposed technology and (ii) analyses Hyperloop technology developments using a triple-helix innovation approach, using a structured methodology based on consolidated data sources (i.e., the Scopus database of peer-reviewed literature and the Patstat patent database). The performed analyses highlight the significant amount of research and patent activity on several aspects of Hyperloop, while the mapping of activities carried out by industry in Europe, as well as from European Services, highlights the progress made towards the future Hyperloop implementation in Europe. Altogether, these findings provide factual information regarding the necessary research, policy, and industry steps taken so far that can help bring Hyperloop into the market. To the authors' knowledge this represents a very systematic and extensive literature review on Hyperloop's scientific and technological developments.
\end{abstract}

Keywords: Hyperloop; disruptive technologies; research; innovation; knowledge management; policy support

\section{Introduction}

Transport is one of the main pillars of society, comprising a spectrum of individual systems and their interconnections that are intended to cover the mobility demand of people and goods. Transport systems include physical and organizational elements and are characterized by an overall intrinsic complexity. These elements can influence each other directly and/or indirectly, linearly or nonlinearly, having also potential feedback cycles [1]. In this sense, the transport system can be considered as an intrinsically very dynamic complex, large-scale, interconnected, open, socio-technical (CLIOS) system [2]. Even though existing transport modes (rail, road, air, and waterborne transport) have experienced many incremental improvements regarding their efficiency, safety, and reliability, during the past few years, paradigm shifts are emerging, supported by the increasing automation and advances in information and communication technology (ICT) [3]. New technologies, social change, and regulatory pressures are creating innovation in industry segments and industry structure as 
well as at the social level [4]. Examples range from taxi services that have been disrupted by new smartphone-enabled services, the shift from car ownership to pay for use, the rise in self-employment due to ride-hailing platforms and, more notably, the advent of connected and automated vehicles [5].

One of the promising future transport technologies is the Hyperloop. Even though the concept of moving "pods" within a "tube" is not new, Hyperloop has received extensive media coverage since the publication of the Hyperloop Alpha white paper by technology entrepreneur Elon Musk in 2013 [6]. Hyperloop consists in pods travelling in high speed (close to $1000 \mathrm{~km} / \mathrm{h}$ ) inside special tube structures in partial vacuum. The initial hype was soon followed by several companies engaging in Hyperloop research and development, while many others already operating in other sectors (e.g., railway, aviation) started to design and manufacture components and parts necessary for Hyperloop deployment. More recently, a number of Hyperloop companies started planning the building of testing tracks in Europe. The potential of Hyperloop as a potentially disruptive technology is boosted if it is seen as an alternative to high-speed trains [7].

Hyperloop can also contribute to the reduction of $\mathrm{CO}_{2}$ emissions, supporting the advancement of the European Union's (EU) Green Deal objectives that seek a 90\% reduction of the EU's greenhouse gas (GHG) emissions by 2050 [8], as well as global GHG emissions reduction commitments. Transport currently accounts for a quarter of the EU's GHG emissions [9], seeing an increase over the last three years [10]. Due to the fact that Hyperloop moves in a low-pressure environment, the air resistance (drag) is in principle lower compared to trains, with considerably lower energy consumption during acceleration and cruise, while energy regeneration during breaking is higher compared to high-speed trains [11]. The prospect of low energy consumption, as well as the possibility of this energy coming from renewable sources, allows the Hyperloop technology to position itself as sustainable and as a contributor to the United Nation's Sustainable Development Goals (mainly to SDGs 11, 13, and 15 on sustainable cities, climate action, and life on land, respectively [12]).

The role of targeted policy initiatives is key to promote and foster the adoption of new technologies and services such as Hyperloop. Nevertheless, issues persist that also go beyond policy or for which it is difficult to formulate appropriate policies, e.g., technology acceptance, bottlenecks in the design and implementation phase of new technologies and services, and the fragmentation of different technologies and standards in the transport domain [13]. However, targeted policy actions can help alleviate these issues. A notable example is technology acceptance, which for a new transport mode is linked to the perceived safety risks. In this area, an approach similar to the one adopted in the EU for the railway sector can be helpful, addressing the relevant risks and building trust to the relevant technologies. The approach is based on the use of Common Safety Methods (CSMs) and Common Safety Targets (CSTs) established in accordance with Articles 6 and 7 of EU Directive 2016/798 [14], which describe how the safety levels, the achievement of safety targets, and compliance with other safety requirements should be fulfilled in the rail sector, and ensure that safety is maintained at a high level and, when necessary and where reasonably practicable, improved.

Another aspect that remains to be proven is the commercial potential and the economic feasibility of Hyperloop, considering also the large investments required in infrastructure, strongly linked to land implications that vary for different landscapes [15]. Although a lot depends on the capacity of the system, which varies among different Hyperloop technologies, the general consensus is that it is significantly lower than high-speed rail [16]. When considering Hyperloop as an alternative to air transport, studies argue that potential Hyperloop corridors can have a substantial short-term impact on airport competition [17]. An early report focusing on the commercial feasibility analysis of Hyperloop identifies key issues that need answers before providing a definitive answer [18]. Very recently, a comprehensive independent feasibility study argues in favor of the profitability and economic benefits of a specific Hyperloop route in the US [19].

Nevertheless, even though many Hyperloop promoters are planning Hyperloop test tracks, we are still far from building a full-scale prototype track long enough to showcase the full potential of Hyperloop as a new mode of transport and field-test the safety and reliability of Hyperloop 
technologies. Furthermore, while a lot has been made public on the technical feasibility of Hyperloop, literature on safety and security, including identification and assessment of risks (see for example [20]), is rather limited.

As a matter of fact, even if Hyperloop is in large part based on existing subsystems, already tested individually, reliability of the subsystems does not necessarily imply the reliability of the system as a whole, and safety assurance provided for a given system is specific to that system in its certified configuration [21]. New challenges will also arise from specific issues never tested before (e.g., evacuation of pods in partial vacuum conditions).

From a safety perspective, increasing (interactive) complexity, more complex relationships between humans and automation, and changing regulatory and public views of safety (the latter with various forms of oversight and regulation from the institutions) are challenging both traditional accident models and accident prevention and risk assessment techniques [22]. For this, it is common for new complex systems to define appropriate serviceability and structural integrity limit-states for the system life-cycle and link them to acceptable damage levels [23].

Considering the complexities mentioned above, there is a pressing need to inquire about the safety, security, availability, and reliability of Hyperloop. As extensive research has been done on the safety and risk assessment in other transport sectors, a suitable approach is to build on existing practices, rules, and knowhow, including the avail of existing codes and standards. These may cover transport modes (rail, aviation, but also to a lesser extent, road and waterborne), but also sectors that can provide solutions in specific areas, for example, civil engineering (for sub-structures and tubes), space technologies, or pipelines (tube-pod interfaces). Experience gained in previous studies, in particular on maglev trains, can be useful [24].

In addition, Hyperloop technologies are rapidly and dynamically evolving, something that adds to the complexity. Very recently, Hyperloop promoters presented (proprietary) technologies that alter the state of play in the field. These developments may lead to performance improvements, but also to possible vulnerabilities that need to be assessed.

Overall, as Hyperloop is a new technology operating under conditions that reach the edge of human endeavor, it inevitably raises concerns about the safety of its operation. There is no doubt that travelling for long distances at almost sonic speeds, under near vacuum conditions, and with very limited or zero maneuverability, constitutes a high hazard situation. Still, the level of risk can be reduced to acceptable levels, provided that the appropriate safety systems are put in place (see for example [25]).

Considering the above, this study recognizes that energy consumption, safety and serviceability, and financial feasibility are essential elements contributing to the sustainability of the Hyperloop technology, as well as to its importance in contributing to the global sustainable goals. Thus, it follows a two-tier approach for the analysis, which (i) addresses the safety concerns and provides preliminary risk-analysis considerations for the safe implementation of Hyperloop, and (ii) analyses Hyperloop technology developments, applying the methodology co-developed by one of the authors for the European Commission's Transport Research and Innovation Monitoring and Information System (TRIMIS) [26].

To achieve this objective, a triple-helix innovation approach is used [27], in which efforts from academia (scientific publications), the industry (patents), and the government (in the form of possible initiatives linked to future policy actions) are assessed (Figure 1). The reasoning behind this approach, is that in the case of Hyperloop, which is fundamentally a new system, it creates the need for new basic research that focuses on new processes and challenges. Likewise, as the technology becomes more mature, adequate governance needs to address it from a policy perspective, focusing on safety and accounting for other issues such as standardization and certification. The whole process is anything but linear, and several links between the three elements are possible. 

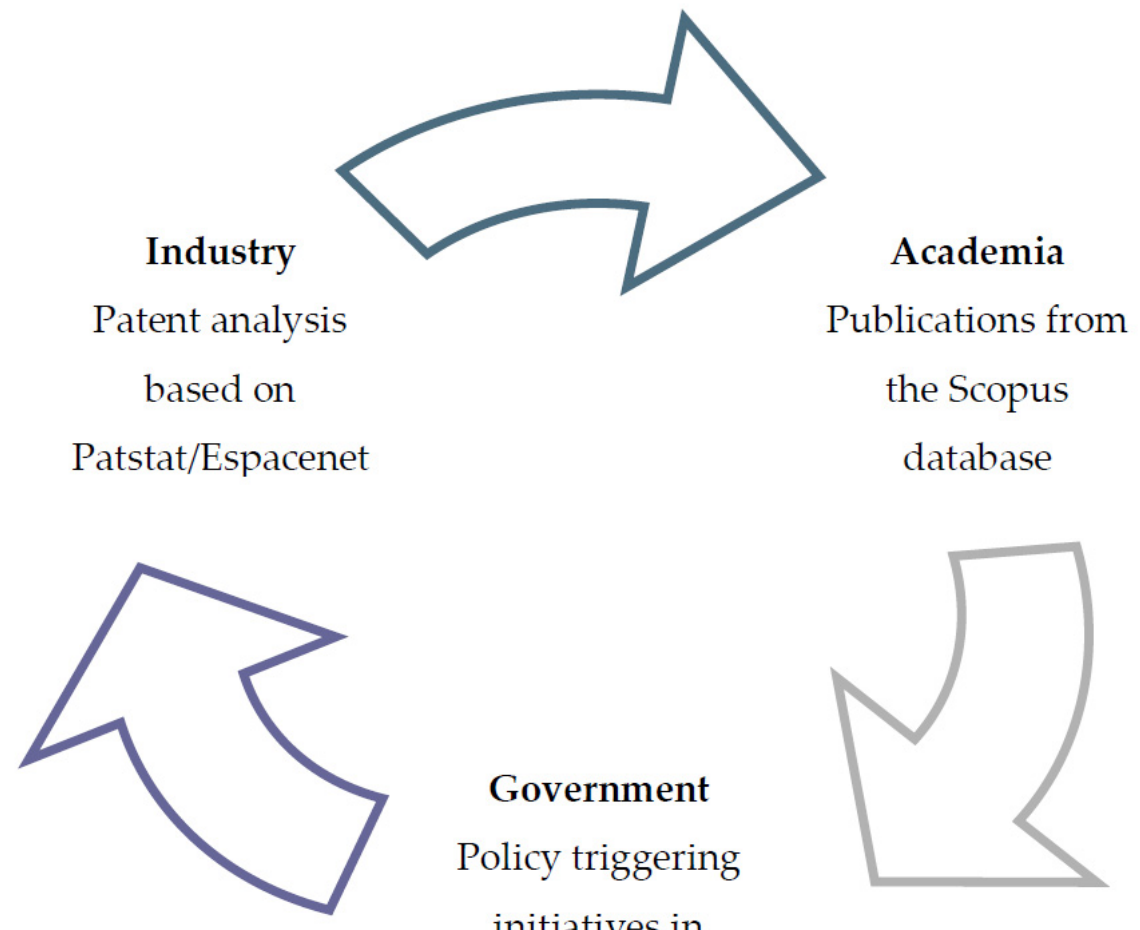

\section{Government}

Policy triggering

initiatives in

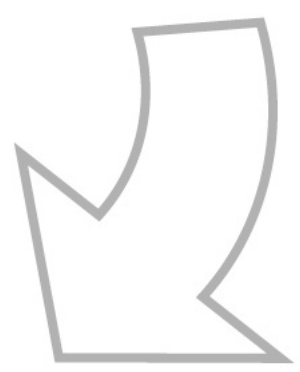

Europe

Figure 1. A triple-helix approach to assess Hyperloop developments (source: own elaboration).

By identifying and clustering efforts from the academia, the research interest is highlighted, focusing on individual technical issues, while the patent activity shows the trend of the interest from industry, investing in Hyperloop technologies. Finally, efforts from the government show the interest from the people's perspective in fostering Hyperloop developments.

\section{Methodological Background}

In order to study the problems linked to the deployment of Hyperloop systems, an inclusive and holistic system of systems approach is necessary, accounting for interdependencies and interactions between the different systems and subsystems that support and interact with the Hyperloop ecosystem. To this end, this study starts with a system decomposition that can be a starting point for risk-analysis considerations and helps identify issues and areas of Hyperloop research. The rest of this section focuses on the methodology behind the scientific research analysis and the intellectual property (patent) analysis.

\subsection{System Decomposition}

While Hyperloop is a new transportation mode in which there is limited or no experience on its operation as a whole, there is sufficient experience in the operation of many of its subsystems, as well as experience in similar systems from other sectors, which, after thorough analysis of the risks, can address all safety challenges and guarantee that risks remain low at all times.

A first step is to perform a system decomposition of Hyperloop into different parts and analyze their interdependencies (including interactions with external systems). This is because the decisions taken, especially in the design process, are based on the knowledge obtained about the object of study [28].

This can be done using a system approach in which the lowest aggregation breaks down the Hyperloop system. Four macro areas are identified: 
- Substructure (including foundations and bridge work)

- Tube

- Pod

- Interface (pod-tube)

Figure 2 provides a schematic of the decomposition.

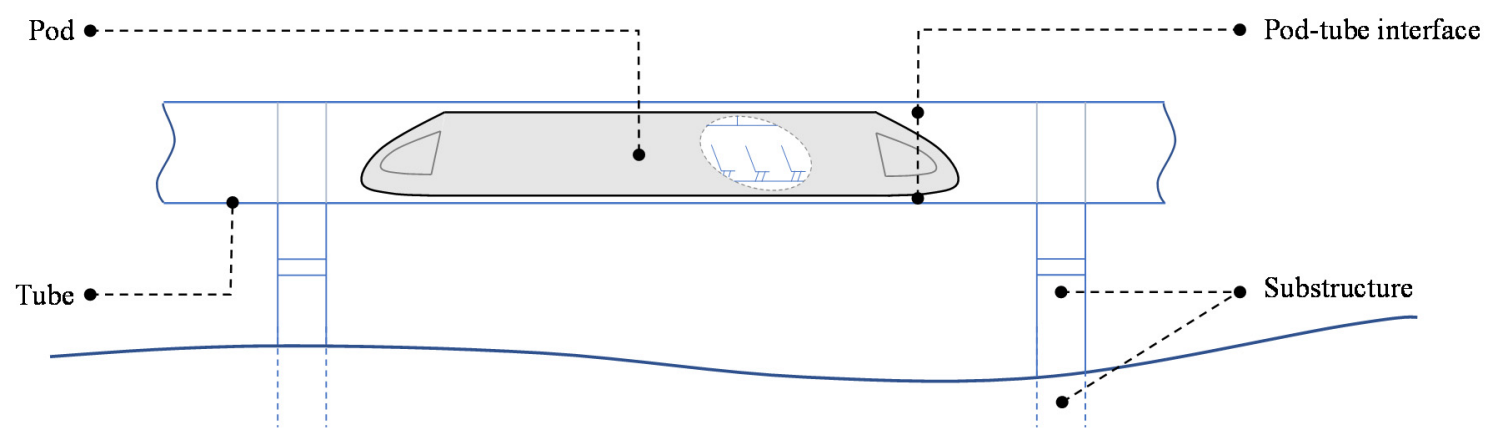

Figure 2. Hyperloop system decomposition (source: own elaboration).

This decomposition is used to identify possible risk issues, as well as cluster research issues from scientific literature and patent topics from patent activity in Section 3.

\subsection{Scientific Research and Patent Analysis}

Even though Hyperloop is a relatively new system, research has already been performed on its performance and safety challenges, as well as on other issues (e.g., commercial feasibility). In addition, Hyperloop promoters have registered proprietary technologies through patent filings.

The objectives of the methodology presented below are to capture research findings and to identify international patent activity, in order to identify trends and key research organizations and countries.

To achieve the first objective, the Scopus database was used, which has strict indexing rules, something that makes the quality of the results relatively valid. For the analysis, the following steps were taken:

- A search was carried out focusing on the keywords in "Hyperloop" or "tube transport" in the abstract, title, or keywords. Results were limited to those after 2013 (when the modern concept of Hyperloop was introduced) and to conference or journal papers (articles). The exact query used was: TITLE-ABS-KEY ("Hyperloop" OR "tube transport" OR “tube transportation") AND PUBYEAR > 2013 AND (LIMIT-TO (SRCTYPE, “j”) OR LIMIT-TO (SRCTYPE, “p”)). This search, performed in September 2020, provided 162 results.

- A further manual filtering of the documents based on the title or abstract one-by-one limited the results to 91 documents. The aim of this filtering was to eliminate those documents that were not relevant to the field due to lexical ambiguity and those that simply outlined Hyperloop-related aspects. This left 52 articles and 39 conference papers.

- After this step, all papers were read and analyzed. Following that, an attempt was made to assess quantitatively research under several clusters. The decomposition from Section 2.1 was adopted, together with four additional vertical clusters (energy, safety, aerodynamics, and operations) and two that focused on general discussions and Hyperloop network development.

To achieve the second objective, the most recent Patstat dataset was used [29], which covers patents published up to early spring 2020. The dataset is currently being implemented in the TRIMIS database [30]. While data accuracy in Patstat is not without concerns [31], the performed analyses aimed to overcome this issue with adequate filtering and by checking the results one-by-one. For the analysis, the following steps were taken: 
- First, the relevant cooperative patent classification (CPC) codes were identified. In this case, CPC code B61B13/10 ("other railway systems, tunnel systems (pneumatic tubes conveyors)") was the most relevant to Hyperloop.

- Second, the earliest filing year was set as 2014 or later.

- Third, the patents belonging to the same patent family (i.e., set of patents taken in various countries to protect a single invention) were counted once, keeping the earliest entry.

- Finally, patent descriptions were checked one-by-one to assert that they were relevant to Hyperloop technologies, leading to the identification of 46 patents.

Table 1 reassumes the search coverage of the two tasks.

Table 1. Scientific research and patent analysis coverage overview (source: own elaboration).

\begin{tabular}{ccc}
\hline & \multicolumn{1}{c}{ Scientific Research Analysis } & \multicolumn{1}{c}{ Patent Analysis } \\
\hline Data & \multicolumn{1}{c}{ Scopus dataset } & \multicolumn{1}{c}{ Patstat dataset } \\
\hline Timeframe & After 2014 (2020 partially covered) & $\begin{array}{l}\text { After 2014 (covering up to early } \\
\text { spring 2020) }\end{array}$ \\
Search type & $-\quad \begin{array}{l}\text { Text search on title, abstract } \\
\text { and keywords. } \\
\text { Search keywords: “Hyperloop"; } \\
\text { "tube transport"; } \\
\text { "tube transportation } \\
\text { Manual check and validation of } \\
\text { the results base on the abstracts }\end{array}$ & $\begin{array}{l}\text { Patent classification code: B61B13/10 } \\
\text { "other railway systems, tunnel } \\
\text { systems (pneumatic tubes conveyors)" } \\
\text { Manual check and validation of the } \\
\text { results based on the } \\
\text { patent descriptions }\end{array}$ \\
\hline Other details & $\begin{array}{l}\text { Limited to articles and } \\
\text { conference publications }\end{array}$ & Patents clustered based on common families \\
\hline
\end{tabular}

For additional details on the methodology, the reader is referred to the TRIMIS methodology for the identification and assessment of new and emerging technologies and trends (NETT) in the transport sector $[32,33]$.

\section{Analyses and Results}

Focusing on the considerations made in Section 1 and the methodology presented in Section 2, the following paragraphs present and discuss the main findings of the analysis.

\subsection{Preliminary Considerations for Risk Analysis}

As Hyperloop is a new technology operating under conditions that reach the edge of human endeavor, it inevitably raises concerns about the safety of its operations. There is no doubt that travelling for long distances at almost sonic speeds, under near vacuum conditions and with very limited or zero maneuverability, constitutes a high hazard situation.

As a first step, starting from the decomposition performed in Figure 2, it is possible to identify possible legislative, technological, and other challenges and enablers for the introduction of Hyperloop, considering what has been done in aviation, rail, and road, as well as in other sectors (Table 2).

Table 2. Similarities with existing transport modes and technologies (source: own elaboration).

\begin{tabular}{cccccc}
\hline Hyperloop & Aviation & Rail & Road & Maritime & Space \\
\hline Substructure & - & High & High & - & - \\
Tube & Low & Low & - & - & - \\
Interface & Low-High & - & - & - & High \\
Pod & High & High & - & Low & High \\
\hline
\end{tabular}


Regarding the substructure for example, there are strong similarities with highway and railway bridge structures. However, there are points for further investigation compared to the state of art: the serviceability and safety limit-states need to be addressed within Hyperloop requirements, and the loading system has different characteristics. The European Standards for Structural Design (Eurocodes) provide the framework for the structural analysis [34]. Hyperloop substructure design can be facilitated by recent work on the standardization needs for the design of underground structures in Europe ([35]).

The tube itself, shares similarities with tunnel structures. Minimum superstructure requirements for safety and serviceability need to be considered. In this case, the Hyperloop system is more confined and controlled, something that makes less likely the occurrence of catastrophic fires, which were a major issue for road tunnels in particular.

The pod structure is very innovative, yet it shares many similarities with rail and aviation. Acceleration and deceleration limits (induced by passenger stability and wellbeing limits), both in normal service and in emergencies, are crucial for the definition of minimum safety distances (safety headways) that have a direct impact on the system capacity. The redundancy and reliability of life support systems in the case of a catastrophic event need to be tested, and an adequate evacuation time needs to be guaranteed, considering the internal pod geometry. Acceptable tube life conditions and evacuation routes within the tube (including safety exits) need to be guaranteed for the evacuation.

Finally, regarding the pod-tube interface, considering the low pressure in the tube, there are strong similarities with space applications. Standards for docking could be applicable [36].

Addressing risks within a structured risk acceptability criterion and using advanced modelling methods (see for example [37]) is essential. Risk analysis as defined in many International Codes and Standards (e.g., ISO 31,000 [38]) or guidelines $([39,40])$ usually incorporated in a global process of risk management.

Furthermore, evacuation procedures need to be carefully planned, especially when considering the network aspect of Hyperloop, which means having switches for diverging tracks. Failure modes of bridges, tunnels, and pipelines (e.g., from the thermal expansion) need to be considered.

On top of that, natural events triggering technological accidents (Natech) need to be accounted for [41], including multi-hazard risks [42-44]. Natural events can also have a short- or long-term effect on the track stability and can lead to performance drops.

Natural events include:

- Landslides/geotechnical issues (related to the soil morphology and the soil-structure interaction).

- Floods, which can also cause corrosion and displacement of the substructure and eventual damage to the tubes system.

- Earthquakes (for earthquake prone areas).

- Strong winds and aerodynamic instability phenomena (e.g., vortex shedding).

Critical infrastructures, including the transport network, are in general prone to cyberattacks. Security risks (including cybersecurity) are important, as terrorist attacks can have severe consequences, while the long distances make for difficult surveillance.

All of the safety-related concerns, which were briefly accounted above, need to be addressed through a thorough risk assessment, performed rigorously according to the ISO 31,000 standard and taking into account the engineering standards for the design and operation of the different subsystems. This standard defines the steps of a systematic approach to assess the risks and provide insights to the triplet of fundamental questions:

- What can go wrong (and what can cause it)?

- How frequently can it happen?

- What will be the consequences?

This analysis should cover all hazards (i.e., structural, electro-mechanical failures, Natech, security) and should be accompanied by risk evaluation and assessment of the need to introduce additional 
safety measures (risk treatment), with the goal to keep risk as low as reasonably practicable (ALARP). Focusing on the proposed macro-level Hyperloop decomposition, there is an indicative connection between the hazards discussed above and their linking to the Hyperloop system (Table 3). For each hazard-part, the level of interaction is identified from indirect/weak (+) to direct/strong $(+++)$.

Table 3. Identification of macro-level hazards affecting Hyperloop parts (source: own elaboration).

\begin{tabular}{ccccccccccccccc}
\hline & \multicolumn{4}{c}{ Hazards: System Failures } & \multicolumn{3}{c}{ Man-Made } & \multicolumn{3}{c}{ Natural Hazards } \\
\hline $\begin{array}{c}\text { Hyperloop } \\
\text { system }\end{array}$ & $\begin{array}{c}\text { Tube } \\
\text { breach/loss } \\
\text { of pressure }\end{array}$ & $\begin{array}{c}\text { Pod } \\
\text { breach }\end{array}$ & $\begin{array}{c}\text { Fire in } \\
\text { Pod }\end{array}$ & $\begin{array}{c}\text { Power } \\
\text { loss }\end{array}$ & $\begin{array}{c}\text { Loss of } \\
\text { break } \\
\text { capacity }\end{array}$ & $\begin{array}{c}\text { Cyber } \\
\text { attack }\end{array}$ & Landslides & Flood & $\begin{array}{c}\text { Strong } \\
\text { wind }\end{array}$ & Earthquake Other \\
\hline Substructure & + & + & + & + & + & + & +++ & +++ & +++ & +++ & - \\
\hline Tube & +++ & ++ & + & +++ & + & + & ++ & ++ & ++ & ++ \\
\hline Interface & ++ & ++ & ++ & ++ & + & ++ & + & + & ++ & ++ & - \\
\hline Pod & ++ & +++ & +++ & +++ & +++ & +++ & + & & + & + & + & + \\
\hline
\end{tabular}

Interaction: +++: direct/strong; ++: direct/weak or indirect/strong; +: indirect/weak.

An example of the first steps of such an approach is given in [20], where an established hazard identification method (FMECA - failure mode, effects and criticality analysis) is applied to identify and assess the most safety-critical failures in order to conclude that the door failure is the most critical failure of the pod. Following this step, it is expected that a systematic assessment of the preventive and mitigation measures would take place, for example through a bow-tie approach, to identify the measures necessary to ensure a desired safety integrity level (SIL).

As Hyperloop will operate in extreme conditions, with very limited margin for errors, it is important to address all safety issues in the design phase. Nevertheless, human errors cannot be excluded, especially when linked with maintenance operations, changes of procedures, and so forth., as it was tragically demonstrated at the Lathen Maglev train accident in 2006 [45]. These potential errors need to be properly taken into account in the systems' design phase.

Indeed, it has been demonstrated in several technological sectors that accidents trigger both new research and new regulation. Research is triggered immediately after an accident, in order to investigate the causes and to develop the necessary prevention and mitigation measures to prevent its occurrence in the future. However, regulatory needs also manifest themselves after an accident as a direct reaction of the society to the losses. For example, the Three Mile Island nuclear accident in 1979 triggered research that led to a completely new field, the quantitative risk assessment (QRA), with numerous applications in all technological sectors, from nuclear to chemical and to aerospace. It also gave birth to a new philosophy of regulation, the risk-informed safety regulation. Similarly, the Seveso accident in 1976 gave birth to the Seveso Directive for the regulation of the chemical industry, while the big tunnel fire at the Mont Blanc tunnel in 1999 resulted in dedicated legislation for the safety of road tunnels, as well as in the development of tools for the reduction of risks. Therefore, a triple-helix approach and relevant interlinks can be observed among accidents, R\&I, and regulation, aiming at a continuous improvement of safety and finally safer and more sustainable solutions.

It is important for a new and emerging technology to ensure and demonstrate that all risks have been taken into account and are managed to be as low as possible. The role of regulators, standardization bodies, and the insurance industry are essential, especially during the first steps of the new technology (see, for example [46]). Finally, a system for sharing lessons needs to be established amongst the Hyperloop promoters as soon as possible to ensure that lessons from failures are identified and learned.

Finally, user acceptance is very important. Hyperloop should have high safety standards, and for this reason individual safety target risk limits should be aligned with the values currently implemented in railway and civil aviation. The railway fatality risk (fatalities per million train- $\mathrm{km}$ ) in Europe (EU-28) in the period 2012-2016 was lower than 0.6 and the passenger fatality risk (passenger fatalities per 
billion passenger train-km) was lower than 0.11 [47]. In aviation, the fatality risk, measured as the number of full-loss equivalents per 1 million flights, is constantly declining and was 0.11 in 2019 [48].

\subsection{Academic Research on Hyperloop}

Following the steps taken in Section 2.2, Figure 3 shows the outcome of this exercise. As can be seen, the publication trend is positive, considering also that results for 2020 cover only a few months.

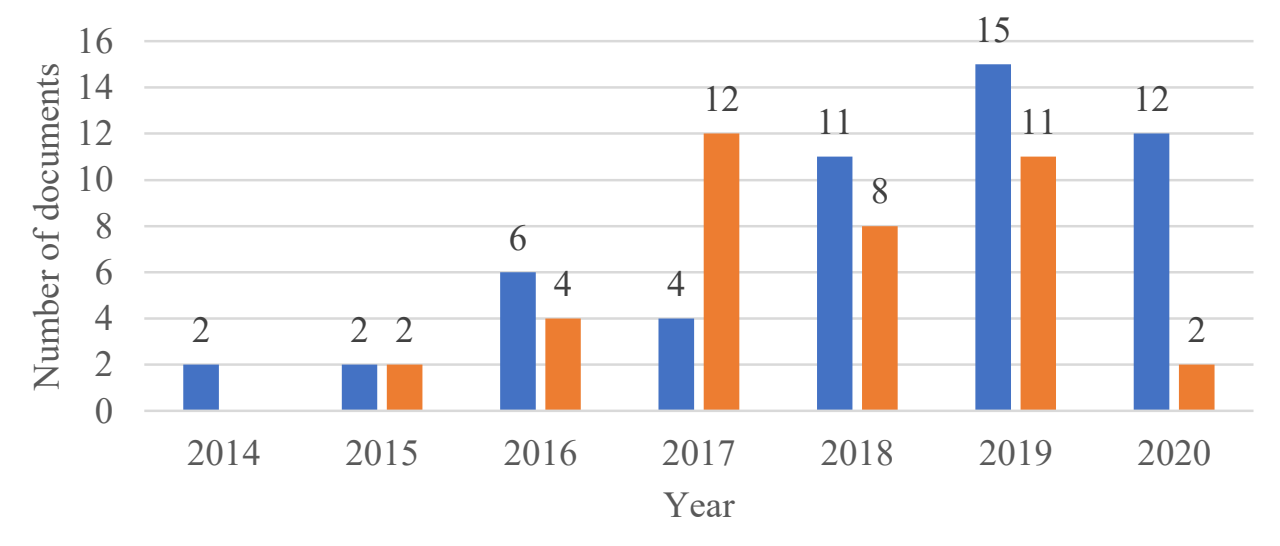

- Article $\quad$ Conference paper

Figure 3. Journal and conference publications on Hyperloop (data source: Scopus; own elaboration).

Following an assessment of the 91 abstracts, the clusters are further defined in Table 4 using a bottom-up approach, and each document is tagged with one cluster from the vertical and one from the decomposition or with one generic cluster (discussion or network). As data are limited to Scopus scientific research, the research topics identified in literature can act as a baseline for future developments, as it is plausible that many Hyperloop promoters carry out research on specific topics without publicly communicating the results.

With the exception of 20 documents on Hyperloop discussions and eight documents on Hyperloop network developments, the one-to-one relationship between vertical and decomposition clusters in the remaining documents is shown in the chord diagram of Figure 4.

This kind of visualization can help identify the most researched topics and their relationships, and at the same time identify deficiencies in research. As can be seen, most research is dedicated to pod and operations (18 documents), pod and aerodynamics (8 documents), and interface and energy (8 documents). Scientific research on safety issues is rather limited, addressed only in 6 documents (three focusing on the pod, two on the tube, and one on the pod-tube interface).

Table 5 provides a selection of recent technology related topics and approaches from the above review, restricted to the last 4 years (from 2017 and onwards) and technology related issues. Although the literature sample considered is not very large, and thus findings cannot be necessarily generalized, they still provide an insightful view on Hyperloop research. 
Table 4. Hyperloop clusters and corresponding research topics from Hyperloop scientific literature (source: own elaboration).

\begin{tabular}{|c|c|c|c|}
\hline & & Clusters & Research Topics \\
\hline \multirow{4}{*}{ Decomposition clusters } & 1 & Substructure & bridge dynamics; geotechnical issues; earthquake forces \\
\hline & 2 & Tube & vacuum level; air tightness \\
\hline & 3 & Pod & $\begin{array}{l}\text { drivetrains; propulsion; suspension; levitation; guidance; } \\
\text { pod design; battery }\end{array}$ \\
\hline & 4 & Interface & levitation friction; blockage ratio; heat generation; energy loss \\
\hline \multirow{4}{*}{ Vertical clusters } & 1 & Energy & $\begin{array}{l}\text { explicit analysis on energy consumption and optimization; } \\
\text { aerodynamics focusing on heat dissipation }\end{array}$ \\
\hline & 2 & Safety & breaking; general safety processes; evacuation; pod tightness \\
\hline & 3 & Aerodynamics & blockage ratio; aerodynamic optimization; aerodynamic noise \\
\hline & 4 & Operations & $\begin{array}{l}\text { Hyperloop operations and research not covered in the } \\
\text { above clusters }\end{array}$ \\
\hline \multirow[t]{2}{*}{ Generic clusters } & 1 & Discussion & $\begin{array}{l}\text { technical feasibility; financing; policy recommendations; new } \\
\text { mobility paradigms; knowledge management; education; } \\
\text { technology overview }\end{array}$ \\
\hline & 2 & Network & financial efficiency; feasibility studies; operations \\
\hline
\end{tabular}

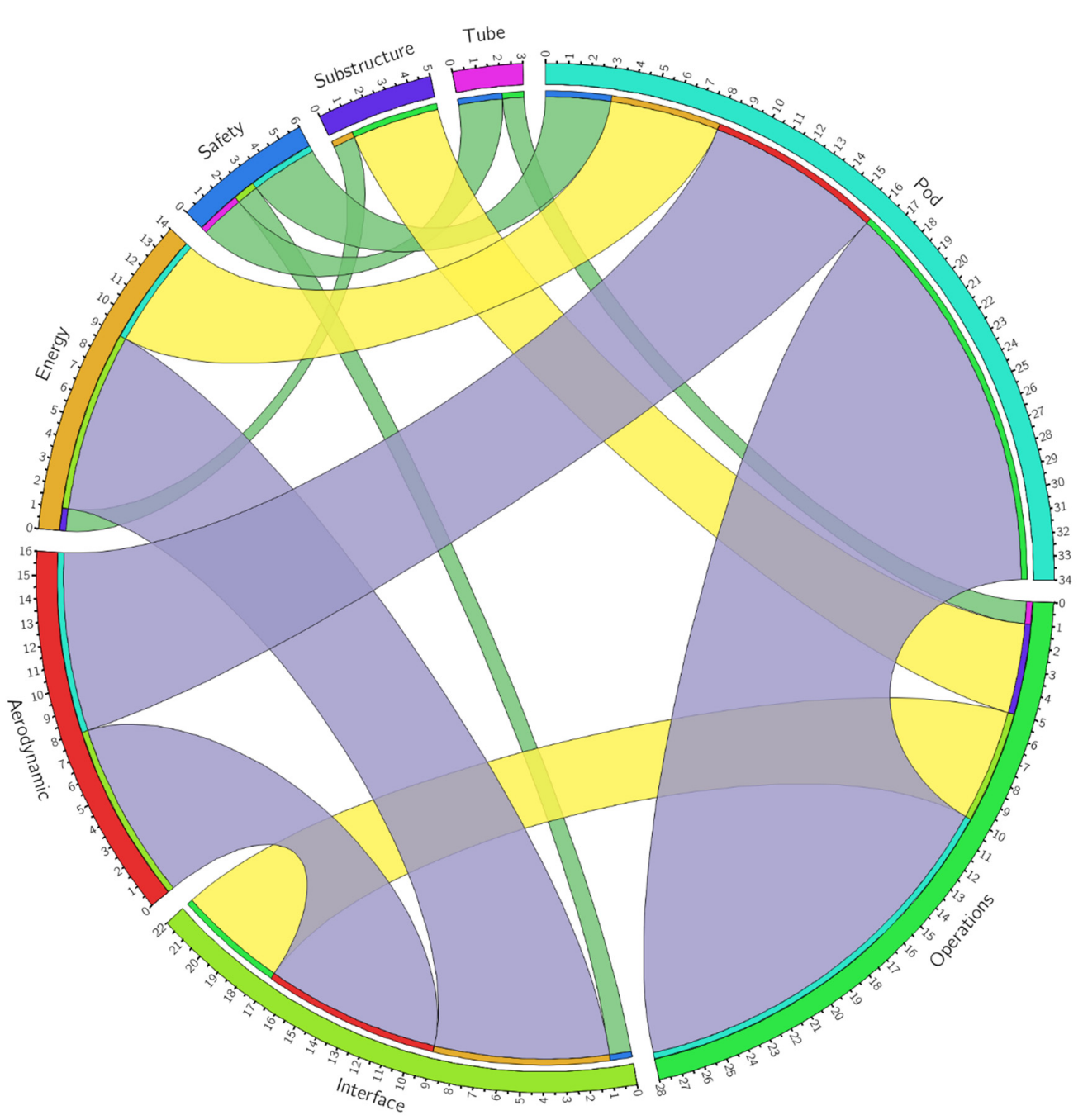

Figure 4. Relationships among research topics in Hyperloop scientific publications (data source: Scopus; own elaboration). 
Table 5. Number of technologies and projects assessed (data source: Scopus; own elaboration).

\begin{tabular}{|c|c|c|}
\hline Authors and Year & Issue & Principal Method \\
\hline Lim et al. 2020 [49] & $\begin{array}{l}\text { Optimization of a high-temperature } \\
\text { superconducting magnet for } \\
\text { subsonic transportation. }\end{array}$ & Simulation \\
\hline Nick and Sato 2020 [50] & $\begin{array}{l}\text { Computational fluid dynamics simulation of } \\
\text { Hyperloop pod predicting laminar-turbulent } \\
\text { transition; aerodynamic analysis for two pod } \\
\text { designs (short and optimized). }\end{array}$ & Analytical, simulation (CFD) \\
\hline Seo et al. 2020 [51] & $\begin{array}{l}\text { Design of propulsion-levitation-guidance } \\
\text { integrated double-sided linear induction motor } \\
\text { with non-symmetric structure. }\end{array}$ & Simulation (FEM) \\
\hline Connolly and Costa 2020 [52] & $\begin{array}{l}\text { Interaction between moving vehicle and vibration } \\
\text { characteristics of the underlying soil-guideway } \\
\text { system. Influence of the vehicle axis position. }\end{array}$ & Simulation \\
\hline Chaidez et al. 2019 [53] & $\begin{array}{l}\text { Minimization of rolling and contact } \\
\text { levitation friction. }\end{array}$ & Analytical \\
\hline Guo et al. 2019 [54] & $\begin{array}{l}\text { Design and analysis of a plate type } \\
\text { electrodynamic suspension structure for a } \\
\text { proposed high-speed maglev/tube system. }\end{array}$ & Computational (FEM) \\
\hline Guo et al. 2019 [55] & $\begin{array}{l}\text { Study of a null-flux coil electrodynamic } \\
\text { suspension structure for evacuated } \\
\text { tube transportation. }\end{array}$ & Computational (FEM) \\
\hline Choi et al. 2019 [56] & $\begin{array}{l}\text { Design of a sub-sonic linear synchronous motor } \\
\text { with high-temperature superconducting magnets. }\end{array}$ & Simulation, experimental \\
\hline Li et al. 2019 [57] & $\begin{array}{l}\text { Embarking and disembarking of pod structure. } \\
\text { Passenger transfer flow. }\end{array}$ & Experimental \\
\hline Nowacki et al. 2018 [58] & $\begin{array}{l}\text { Pod shape optimization focusing on reducing the } \\
\text { energy demand. }\end{array}$ & Numerical models \\
\hline Sayeed et al. 2018 [59] & $\begin{array}{l}\text { Active levitation and propulsion Hyperloop } \\
\text { system. Control, and drive system design. }\end{array}$ & $\begin{array}{l}\text { Numerical, Simulation, } \\
\text { Computational (FEM) }\end{array}$ \\
\hline Dudnikov, 2018 [60] & $\begin{array}{l}\text { Passenger (tube) pressure; tightness in Hyperloop } \\
\text { passenger systems. }\end{array}$ & Analytical \\
\hline Ji et al. 2018 [61] & $\begin{array}{l}\text { Non-Symmetric double-sided linear induction } \\
\text { motor for tube propulsion, magnetic levitation, } \\
\text { and guidance. }\end{array}$ & Computational (FEM) \\
\hline Abdelrahman et al. 2018 [62] & Pod magnetic levitation and propulsion control. & $\begin{array}{l}\text { Analytical, Simulation, } \\
\text { Computational (FEM) }\end{array}$ \\
\hline Goeverden et al. 2018 [63] & $\begin{array}{l}\text { Operational performance, quality of } \\
\text { service, safety. }\end{array}$ & Analytical, review \\
\hline Opgenoord and Caplan, 2018 [64] & Aerodynamic design. & Computational (CFD) \\
\hline Kang et al. 2017 [65] & Aerodynamic drag; aerodynamic design. & Computational (CFD) \\
\hline Heaton 2017 [66] & Earthquake forces. & Analytical \\
\hline Braun et al. 2017 [67] & Aerodynamic design. & Computational (CFD) \\
\hline Jansen 2017 [68] & Propulsion, aerodynamics, vibration. & Computational (CFD) \\
\hline
\end{tabular}

\subsection{Patent Activity on Hyperloop}

Figure 5 shows the outcome in terms of number of patents granted by applicant sector and by the country of origin of the applicant. The majority of patents (27) come from private companies, while nine are filed by government/not profit organizations, nine from Universities, and one by an individual. China leads with 21 patents, followed by the US (13) and Korea (nine), while there are three patents granted from EU Member States, namely France, the Netherlands, and Spain. Focusing on the sector-country split, it is interesting to observe that all 13 US patents come from the private sector (including six from Hyperloop Technologies Inc. and four from the Boeing company), and all nine 
Korean patents come from government/non-profit organizations (six from the Korea Railroad Research Institute and three from the Korea Institute of Construction Technology). CRRC Yangtze Co. leads the entities with patents in China with five cases.

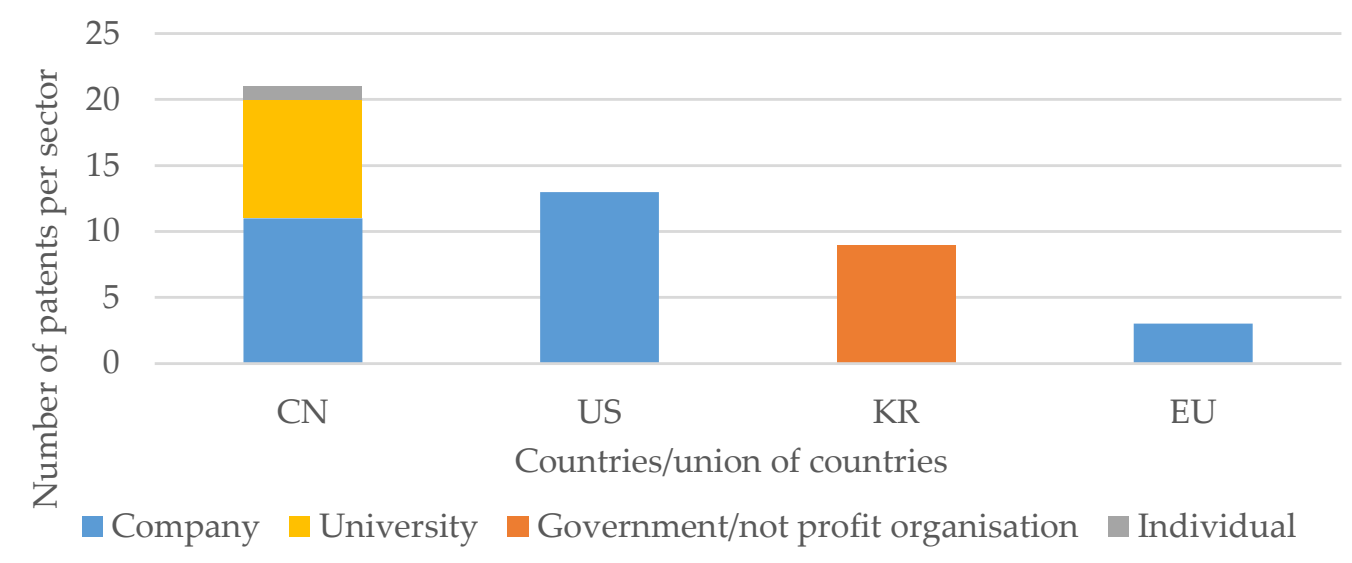

Figure 5. Number of patents granted by applicant sector (data source: PATSTAT; own elaborations).

Figure 6 shows the evolution of granted patents in the period 2014-2018, focusing on the first filling year, and divided by the country of origin of the publication author. As can be observed, patent activity passed from five in 2015 to 10 in 2016 and 20 in 2017. It is expected that there are patents filed in 2018 that are not granted yet.

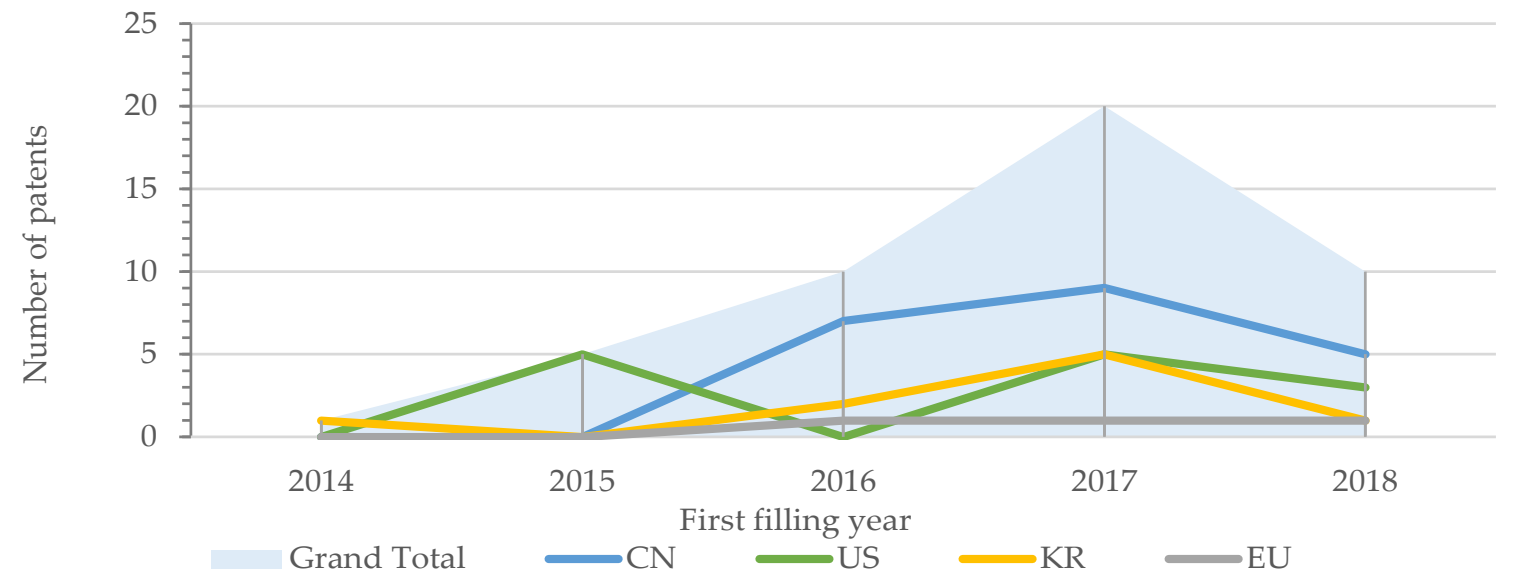

Figure 6. Patent application trends (data source: PATSTAT; own elaborations).

There are still some concerns regarding the analyses, considering that it is a very recent technology, so patents are filed under various patent codes and data issues are common. Furthermore, a similar search on the Espacenet [69], a free online service for searching patents and patent applications, revealed a much larger volume of patent activity, especially from China. However, Espacenet also covers patent applications (not necessarily granted) and cannot be considered as reliable as Patstat, while other reasons (e.g., linked to political decisions) may explain the high number of patent filings from China.

In a similar way to what has been done for scientific research, an effort is made to map these patents within the clusters identified in Section 2.1. Table 6 provides the results. An additional cluster has been added (other) that gathers mostly patents on complete systems and logistics and freight operations. 
Table 6. Hyperloop clusters and corresponding patent topics from Hyperloop patent analysis (source: own elaboration).

\begin{tabular}{ccccc}
\hline & \multicolumn{3}{c}{ Clusters } & \multicolumn{1}{c}{ Patented Topics } \\
\cline { 2 - 4 } Decomposition clusters & 2 & Substructure & $\begin{array}{l}\text { concrete tube construction; tube sealing construction; tube } \\
\text { concrete slab; tube support; underground construction; }\end{array}$ \\
\cline { 2 - 5 } & 3 & Tube & $\begin{array}{l}\text { negative pressure infrastructure; use of a gaseous mixture of } \\
\text { air and helium; temperature reduction using liquid nitrogen; } \\
\text { environment control; vacuum forming }\end{array}$ \\
\cline { 2 - 5 } & Pod & Interface & $\begin{array}{l}\text { vehicle control; direction control; brake apparatus; vehicle } \\
\text { position detection; magnetic propulsion; vehicle stability; } \\
\text { electrodynamic suspension system; breaking; evacuation }\end{array}$ \\
\hline 5 & Other & $\begin{array}{l}\text { cooling of compressed air; vacuum control at docking; } \\
\text { docking system }\end{array}$ \\
\hline
\end{tabular}

It should be noted that there are several (seven in total) earlier patents (from 2015 and 2016) that focus on a Hyperloop complete system. In recent years, and as Hyperloop research has become more mature, patents have focused on specific aspects.

This "intellectual property mapping" helps identify possible areas for synergies within Hyperloop promoters, and identify technology spillovers to other transport modes (rail in particular). The identification of common areas of research, designated by patent activity, is also crucial for the collaboration of different Hyperloop promoters in research and testing toward the interoperability of the system. Finally, new technological developments lead to new sources of risk that need to be accounted for in a continuous risk assessment and monitoring process.

Furthermore, it is possible to identify company-specific innovation and possibly identify areas for further research. As an example, Hardt Hyperloop presented a patented technology, "the switch", a track changing mechanism, which allows the vehicle to pass from one track to another and opens up the concept of networks. This adds additional complexities, as the absence of lane switches made Hyperloop an inherently safer mode. Hyperloop Transportation Technologies also filed patents that have the potential to overcome propulsion challenges within the tube.

It is difficult to draw specific conclusions on the connection between academic research and patent activity. In a modern triple-helix context, funded academic scientific activity leads to research results or applications, which in turn can lead to further development and commercialization from companies [70]. That said, the relationship is far from linear, considering the increasing role of universities as technology hubs and thus their tendency to capitalize research results through the creation of incubators, technology hubs, university spin-offs, and so forth [71]. This is also evident in the analyses, with nine patents coming from Universities. Nevertheless, focusing on the funding sponsor in the scientific analyses, only the Korea Railroad Research Institute is acknowledged as such on two occasions. Notably, Hyperloop Technologies Inc. and The Boeing company (present with 10 patents in the analysis) are not acknowledged as funding sponsors in any research papers. When focusing on the patent descriptions and the scientific research papers, no apparent connections are found among them. A possible explanation is that much of the research from private companies is done in-house or under disclosure agreements.

There are still some limitations of the method applied in this study. Data sources are limited to Scopus scientific research (articles and conference papers) and patents found in the Patstat database. More importantly, it is plausible that many Hyperloop promoters carry out research on specific topics without communicating the results. Consequently, these results should be interpreted with attention. 


\section{Hyperloop Developments in Europe}

This section provides an overview of recent Hyperloop developments in Europe that are not covered either by basic research or patent activity and may call for the need of a policy framework. Even though there are no official policy developments at an EU level, initiatives are taking place in Europe by Hyperloop promoters, which are expected to have an impact and trigger policy developments.

\subsection{Initiatives from Hyperloop Promoters}

Initiatives focus primarily on (i) the creation of testing sites (also creating a connection with local communities), (ii) initiatives to raise funds (regional and private in particular), and, more recently, (iii) initiatives aiming for the standardization of the Hyperloop ecosystem.

Regarding the first point, several Hyperloop promoters are planning testing centers in Europe.

- Hardt Hyperloop supported by the European Institute of Innovation and Technology (EIT) is planning a 3-km test track in the Dutch province of Groningen [72].

- Zeleros is planning a 2-km test track in Valencia to test their technologies to speeds up to $500 \mathrm{~km} / \mathrm{h}$ [73].

- Hyperloop TT is building a full-scale test track in Toulouse, France [74].

On funding initiatives, all Hyperloop promoters are financed by mostly private investments. Zeleros and Hardt have registered projects on the European Investment Project Portal (EIPP) with the aim of reaching potential investors [75].

Finally, on standardization, a big challenge for Hyperloop is the standardization (and certification), including infrastructure. In July 2020, TÜV SÜD and Hyperloop TT published a set of generic guidelines for design, operation, and certification of Hyperloop [76].

The above-mentioned initiatives, culminated in the last two years, are an indication that policy developments are needed to address important issues such as standardization, certification, and above all, safety, both for the testing period but also for future deployment.

\subsection{Developments from European Services}

Although Hyperloop is not addressed in current European policies, there are EU initiatives regarding Hyperloop research and innovation potential, while two more recent initiatives focus on operational aspects and the standardization of Hyperloop.

The 2019 Strategic Transport Research and Innovation Agenda (STRIA) roadmap for connected and automated transport (CAT) identifies mergers between rail and air in Hyperloop as technology and experience transfer potentials from CAT research [77].

In January 2020, the Shift2Rail Joint Undertaking (S2R JU) launched a coordination and support action (CSA) focusing on the concepts of operations, safety cases, functional specification, and operational conditions [78].

In February 2020, the European Committee for Standardization (CEN) and the European Committee for Electrotechnical Standardization (CENELEC) launched a new joint technical committee (TC), CEN/CLC/JTC 20, dedicated to Hyperloop system standardization [79]. The new Joint TC will also benefit from the experience of the rail, space, and pressure equipment standardization in which CEN and CENELEC are already active and in particular with the CEN/TC 256 'Railways applications'. Hyper Poland, Hardt Hyperloop, TransPod, and Zeleros Hyperloop support this initiative.

Beyond Europe, policy developments take place that could trigger policy collaborations. In 2019, the U.S. Department of Transportation (DOT) created the Non-Traditional and Emerging Transportation Technology (NETT) Council, an internal deliberative body tasked with identifying and resolving jurisdictional and regulatory gaps that may impede the deployment of new technology, including Hyperloop [80]. All this considering that new transport technologies may not always fit precisely into the existing regulatory structure. 


\section{Conclusions}

Hyperloop is a new transport technology that has the potential to play a key role toward a future decarbonized transport system. This paper provides a first look at issues and challenges for the successful testing and commercialization of Hyperloop from a European perspective. It also maps Hyperloop intellectual property filings that can help identify both risk sources and research spillovers. The issues are presented in a structured manner and are commented on regarding the way forward, providing links to existing systems, analyses, and standards.

The proposed three-step process and the system decomposition provides support to the identification of Hyperloop technological developments and the deriving risks, thus offering insights into the sector's stakeholders, while backing the current transport systems' decarbonization through technological advances. To the authors' knowledge, this represents a very systematic and extensive literature review on Hyperloop's scientific and technological developments.

Regarding scientific research carried out on Hyperloop, a first analysis focusing on identified Hyperloop clusters (substructure-tube-pod interface) leads to the following conclusions:

- most of the research is dedicated to pod and operations (18 documents), pod and aerodynamics (eight documents) and interface and energy (eight documents).

- research on safety issues is rather limited, addressed only in six documents (three focusing on the pod, two on the tube, and one on the pod-tube interface).

Regarding patents granted on Hyperloop:

- it is interesting to observe the differences between countries, with all 13 US patents coming from the private sector and all nine Korean patents coming from government/non-profit organizations.

- patents granted earlier (2015-2016) focus on the entire Hyperloop system and therefore are more conceptual. In the last years, patents focus on specific technical issues, something that shows the higher maturity achieved.

These findings, despite the limitations in the availability of data (restricted to Scopus and Patstat datasets), represent a very systematic literature analysis on Hyperloop scientific and technological developments. In addition, the mapping of activities carried out by industry in Europe, as well as from European Services, highlights the progress made toward future Hyperloop implementation in Europe and the dynamics of the technology.

The findings can also provide a starting point for policy support for future decisions regarding Hyperloop testing and deployment in Europe. For example, policy makers can use these findings to obtain a snapshot of the research and patent activity, and consequently an indication of the maturity of Hyperloop subsystems and functionalities. This process will require, among other thing, continuous identification and analysis of issues, also beyond technology, that will help pave the way towards the demonstration and implementation of Hyperloop. Beyond the importance of this analysis for policy makers, this paper and the associated triple-helix assessment methodology can make several contributions to transport scholars and practitioners who are interested in the development of Hyperloop technologies, for example by identifying synergies between research topics identified for Hyperloop and research topics relevant to existing transport modes.

Author Contributions: Conceptualization: K.G.; formal analysis: K.G.; investigation: K.G. and M.C.; methodology: K.G.; validation: M.C.; visualization: K.G.; writing—original draft: K.G.; writing—review and editing: K.G. and M.C. All authors have read and agreed to the published version of the manuscript.

Funding: This research received no external funding.

Acknowledgments: The views expressed here are purely those of the authors and may not, under any circumstances, be regarded as an official position of the European Commission. Fruitful discussions on patent analysis with JRC colleague Fabio Marques dos Santos and Mitchell van Balen (European Union Agency for Railways) are greatly acknowledged. An earlier version of this paper was originally submitted to TRA2020.

Conflicts of Interest: The authors declare no conflict of interest. 


\section{Glossary}

\begin{tabular}{|c|c|}
\hline ALARP & As Low As Reasonably Practicable \\
\hline CAT & Connected and automated transport \\
\hline CEN & European Committee for Standardization \\
\hline CENELEC & European Committee for Electrotechnical Standardization \\
\hline CFD & Computational Fluid Dynamics \\
\hline CLIOS & Complex, Large-scale, Interconnected, Open, Socio-technical \\
\hline $\mathrm{CN}$ & China \\
\hline СPC & Cooperative patent classification \\
\hline CSA & Coordination and Support Action \\
\hline CSMs & Common Safety Methods \\
\hline CSTs & Common Safety Targets \\
\hline DOT & Department of Transportation \\
\hline EIPP & European Investment Project Portal \\
\hline EIT & European Institute of Innovation and Technology \\
\hline EU & European Union \\
\hline FEM & Finite Element Method \\
\hline FMECA & Failure Mode, Effects \& Criticality Analysis \\
\hline GHG & Greenhouse gas \\
\hline ICT & Information and communication technology \\
\hline ISO & International Organization for Standardization \\
\hline JRC & Joint Research Centre \\
\hline KR & Republic of Korea \\
\hline Natech & Natural events triggering technological accident \\
\hline NETT & New and emerging technologies and trends \\
\hline NETT & Non-Traditional and Emerging Transportation Technology \\
\hline QRA & Quantitative Risk Assessment \\
\hline S2R JU & Shift2Rail Joint Undertaking \\
\hline SDG & United Nation's Sustainable Development Goals \\
\hline SIL & Safety Integrity Level \\
\hline STRIA & Strategic Transport Research and Innovation Agenda \\
\hline TC & Technical Committee \\
\hline TRIMIS & Transport Research and Innovation Monitoring and Information System \\
\hline US & The United States of America \\
\hline
\end{tabular}

\section{References}

1. Cascetta, E. Transportation Systems Engineering: Theory and Methods; Springer: Boston, MA, USA, 2001; Volume 49.

2. Sussman, J.M.; Dodder, R.; McConnel, J.; Mostashari, A.; Sgouridis, S. The "CLIOS Process"—A User's Guide; MIT: Boston, MA, 2009.

3. Rodrigue, J.-P. The Geography of Transport Systems, 5th ed.; Routledge: New York, NY, USA, 2020; p. 456, ISBN 978-0-367-36463-2.

4. Millar, C.; Lockett, M.; Ladd, T. Disruption: Technology, innovation and society. Technol. Forecast. Soc. Chang. 2018, 129, 254-260. [CrossRef]

5. Alonso Raposo, M.; Ciuffo, B.; Alves Dies, P.; Ardente, F.; Aurambout, J.-P.; Baldini, G.; Baranzelli, C.; Blagoeva, D.; Bobba, S.; Braun, R.; et al. The Future of Road Transport-Implications of Automated, Connected, Low-Carbon and Shared Mobility; Publications Office of the European Union: Luxembourg, 2019; ISBN 978-92-76-14318-5.

6. Space-X. Hyperloop Alpha. 2013. Available online: https://www.spacex.com/sites/spacex/files/hyperloop_ alpha-20130812.pdf (accessed on 25 July 2020).

7. Nikitas, A.; Kougias, I.; Alyavina, E.; Njoya Tchouamou, E. How Can Autonomous and Connected Vehicles, Electromobility, BRT, Hyperloop, Shared Use Mobility and Mobility-As-A-Service Shape Transport Futures for the Context of Smart Cities? Urban Sci. 2017, 1, 36. [CrossRef] 
8. European Commission. The European Green Deal COM/2019/640 Final; European Commission: Brussels, Belgium, 2019.

9. European Commission. Sustainable Transport: What Do We Want to Achieve? 2020. Available online: https://ec.europa.eu/transport/themes/sustainable_en (accessed on 25 July 2020).

10. European Environment Agency. Progress of EU Transport Sector towards Its Environment and Climate Objectives; Transport, Environment policy and protection of the environment; Briefing no. 15/2018; European Environment Agency: Copenhagen, Denmark, 2018. [CrossRef]

11. Riviera, M. High-Speed Trains Comparison to Hyperloop: Energy, Sustainability and Safety Analysis Hyperloop Integrations to Reach the NOAH Concept. Master's Thesis, Corso di laurea magistrale in Ingegneria Energetica e Nucleare (Advisor: Andrea Carpignano). Politecnico di Torino, Torino, Italy, 2018.

12. Sachs, J.D.; Schmidt-Traub, G.; Mazzucato, M.; Messner, D.; Nakicenovic, N.; Rockström, J. Six transformations to achieve the sustainable development goals. Nat. Sustain. 2019, 2, 805-814. [CrossRef]

13. Tsakalidis, A.; Gkoumas, K.; Pekár, F. Digital Transformation Supporting Transport Decarbonisation: Technological Developments in EU-Funded Research and Innovation. Sustainability 2020, 12, 3762. [CrossRef]

14. European Parliament, Council of the European Union. Directive (EU) 2016/798 of 11 May 2016 on railway safety (recast). Off. J. Eur. Union 2016, L136, 102.

15. Walker, R. Hyperloop: Cutting through the Hype. Available online: https:/trl.co.uk/sites/default/files/ Hyperloop\%20white\%20paper.pdf (accessed on 25 July 2020).

16. Doppelbauer, J. Hyperloop-An Innovation for Global Transportation? Available online: https://www. era.europa.eu/sites/default/files/library/docs/hyperloop_innovation_for_global_transportation_en_1.pdf (accessed on 25 July 2020).

17. Voltes-Dorta, A.; Becker, E. The potential short-term impact of a Hyperloop service between San Francisco and Los Angeles on airport competition in California. Transp. Policy 2018, 71, 45-56. [CrossRef]

18. Taylor, C.L.; Hyde, D.J.; Barr, L.C. Hyperloop Commercial Feasibility Analysis: High Level Overview. Available online: https://rosap.ntl.bts.gov/view/dot/12308 (accessed on 25 July 2020).

19. TEMS. Great Lakes Hyperloop Feasibility Study by NOACA, HTT, and TEMS. Available online: https:// df8e02a7-c9d7-45bc-89b0-ebfa2d7bf712.filesusr.com/ugd/96eba3_e0b8f11c5e4548f9b4fdc6e1cdd00d6d.pdf (accessed on 25 July 2020).

20. Sarin, M.; Overton, M. Complex Hyperloop Capsule Safety Requirements and Risk Mitigations. In Proceedings of the 36th International System Safety Conference, Phoenix, AZ, USA, 13-17 August 2018.

21. Verhulst, E.; Sputh, B.; Van Schaik, P. Antifragility: Systems engineering at its best. J. Reliab. Intell. Environ. 2015, 1, 101-121. [CrossRef]

22. Leveson, N. A new accident model for engineering safer systems. Saf. Sci. 2004, 42, 237-270. [CrossRef]

23. Bontempi, F.; Giuliani, L.; Gkoumas, K. Handling the exceptions: Dependability of systems and structural robustness. In Proceedings of the 3rd International Conference on Structural Engineering, Mechanics and Computation (SEMC 2007), Cape Town, South Africa, 10-12 September 2007.

24. Geerlings, H. The rise and fall of new technologies: Maglev as technological substitution? Transp. Plan. Technol. 1998, 21, 263-286. [CrossRef]

25. Christou, M. Introduction to risk concepts. In Risk Assessment and Management in the Context of the Seveso II Directive; Kirchsteiger, C., Christou, M.D., Papadakis, G.A., Eds.; Elsevier: Amsterdam, The Netherlands, 1998.

26. Tsakalidis, A.; van Balen, M.; Gkoumas, K.; Pekar, F. Catalyzing Sustainable Transport Innovation through Policy Support and Monitoring: The Case of TRIMIS and the European Green Deal. Sustainability 2020, 12, 3171. [CrossRef]

27. Etzkowitz, H.; Leydesdor, L. The dynamics of innovation: From National Systems and "Mode 2" to a Triple Helix of university-industry-government relations. Res. Policy 2000, 29, 109-123. [CrossRef]

28. Simon, H.A. The Sciences of the Artificial; The MIT Press: Cambridge, UK, 1998.

29. PATSTAT. 2020. Available online: https://www.epo.org (accessed on 25 July 2020).

30. Van Balen, M.; Ortega Hortelano, A.; Grosso, M.; Tsakalidis, A.; Gkoumas, K.; Haq, G.; Pekar, F. EU Transport Research E Innovation Status Assessment Report: An Overview Based on the Transport Research and Innovation Monitoring and Information System (TRIMIS) Database; Publications Office of the European Union: Luxembourg, 2019; ISBN 978-92-76-09006-9.

31. Pasimeni, F. SQL query to increase data accuracy and completeness in PATSTAT. World Patent Inf. 2019, 57, 1-7. [CrossRef] 
32. Gkoumas, K.; Tsakalidis, A. A framework for the taxonomy and assessment of new and emerging transport technologies and trends. Transport 2019, 34, 455-466. [CrossRef]

33. Gkoumas, K.; Marques Dos Santos, F.; Tsakalidis, A.; Van Balen, M.; Ortega Hortelano, A.; Grosso, M.; Pekar, F. New and Emerging Transport Technologies and Trends in European Research and Innovation Projects; EUR 30360 EN; Publications Office of the European Union: Luxembourg, 2020; ISBN 978-92-76-21533-2. [CrossRef]

34. EU Science Hub. Standards in Construction: The Eurocodes. 2020. Available online: https://ec.europa.eu/jrc/ en/research-topic/standards-construction-eurocodes (accessed on 25 July 2020).

35. Athanasopoulou, A.; Bezuijen, A.; Bogusz, W.; Bournas, D.; Brandtner, M.; Breunese, A.; Burbaum, U.; Dimova, S.; Frank, R.; Ganz, H.; et al. Standardisation Needs for the Design of Underground Structures; EUR 29633 EN; Publications Office of the European Union: Luxembourg, 2019. [CrossRef]

36. ESA. International Docking System Standard (IDSS). 2016. Available online: https://www. internationaldockingstandard.com/ (accessed on 25 July 2020).

37. Gkoumas, K.; Di Santo, C.; Bontempi, F. Risk analysis for severe traffic accidents in long road tunnels. Int. J. Forensic Eng. 2016, 3, 106-126. [CrossRef]

38. ISO. In IEC 31010:2009-Risk Management-Risk Assessment Techniques; IEC: Geneva, Switzerland, 2009.

39. NASA-National Aeronautics and Space Administration. Probabilistic Risk Assessment Procedures Guide for NASA Managers and Practitioners. Available online: https://ntrs.nasa.gov/archive/nasa/casi.ntrs.nasa. gov/20120001369.pdf (accessed on 25 July 2020).

40. IRM/AIRMIC/ALARM-The Institute of Risk Management/The Association of Insurance and Risk Managers/The National Forum for Risk Management in the Public Sector. A Risk Management Standard; Institute of Risk Management: London, UK, 2002.

41. Krausmann, E.; Cruz, A.M.; Salzano, E. Natech Risk Assessment and Management; Elsevier: Amsterdam, The Netherlands, 2017.

42. Bruneau, M.; Barbato, M.; Padgett, J.E.; Zaghi, A.E. State of the Art of Multihazard Design. J. Struct. Eng. 2017, 143. [CrossRef]

43. Girgin, S.; Necci, A.; Krausmann, E. Dealing with cascading multi-hazard risks in national risk assessment: The case of Natech accidents. Int. J. Disaster Risk Reduct. 2019, 35, 101072. [CrossRef]

44. Argyroudis, S.; Mitoulis, S.; Winter, M.; Kaynia, A. Fragility of transport assets exposed to multiple hazards: State-of-the-art review toward infrastructural resilience. Reliab. Eng. Syst. Saf. 2019, 191. [CrossRef]

45. Wikipedia. Lathen Train Collision. 2020. Available online: https://en.wikipedia.org/wiki/Lathen_train_ collision (accessed on 25 July 2020).

46. Munich, R.E. Hyperloop Transportation Technologies Risk Report-Abstract. 2017. Available online: https://www.munichre.com/site/corporate/get/documents_E697748403/mr/assetpool.shared/Documents/ 0_Corporate_Website/6_Media_Relations/Company_News/MunichRe-Risk-Report-Hyperloop-L4.pdf (accessed on 25 July 2020).

47. European Railway Agency. Report on Railway Safety and Interoperability in the EU 2018; Publications office of the European Union: Luxembourg, 2018. [CrossRef]

48. IATA. Safety Report 2019, 56th ed.; IATA: Geneva, Switzerland, 2020.

49. Lim, J.; Lee, C.Y.; Choi, S.; Lee, J.H.; Lee, K.S. Design optimization of a 2G HTS magnet for subsonic transportation. IEEE Trans. Appl. Supercond. 2020, 30, 5203305. [CrossRef]

50. Nick, N.; Sato, Y. Computational fluid dynamics simulation of Hyperloop pod predicting laminar-turbulent transition. Railw. Eng. Sci. 2020, 28, 97-111. [CrossRef]

51. Seo, K.Y.; Park, C.B.; Jeong, G.; Lee, J.B.; Kim, T.; Lee, H.W. A study on the design of propulsion/levitation/guidance integrated DSLIM with non-symmetric structure. AIP Adv. 2020, 10, 025031. [CrossRef]

52. Connolly, D.P.; Costa, P.A. Geodynamics of very high speed transport systems. Soil Dyn. Earthq. Eng. 2020, 130, 105982. [CrossRef]

53. Chaidez, E.; Bhattacharyya, S.P.; Karpetis, A.N. Levitation Methods for Use in the Hyperloop High-Speed Transportation System. Energies 2019, 12, 4190. [CrossRef]

54. Guo, Z.; Zhou, D.; Chen, Q.; Yu, P.; Li, J. Design and analysis of a plate type electrodynamic suspension structure for ground high speed systems. Symmetry 2019, 11, 1117. [CrossRef]

55. Guo, Z.; Li, J.; Zhou, D. Study of a null-flux coil electrodynamic suspension structure for evacuated tube transportation. Symmetry 2019, 11, 1239. [CrossRef] 
56. Choi, S.Y.; Lee, C.Y.; Jo, J.M.; Choe, J.H.; Oh, Y.J.; Lee, K.S.; Lim, J.Y. Sub-Sonic Linear Synchronous Motors Using Superconducting Magnets for the Hyperloop. Energies 2019, 12, 4611. [CrossRef]

57. Li, D.; van der Vegte, W.F.; Geuze, M.; van der Meijs, M.; Mastrigt, S.H. Studying a New Embarking and Disembarking Process for Future Hyperloop Passengers. In Advances in Intelligent Systems and Computing, Proceedings of the 20th Congress of the International Ergonomics Association (IEA 2018), Florence, Italy, 26-30 August 2018; Bagnara, S., Tartaglia, R., Albolino, S., Alexander, T., Fujita, Y., Eds.; Springer: Cham, Switzerland, 2019; Volume 823.

58. Nowacki, M.; Olejniczak, D.; Markowski, J. Assessment of medium parameters in a closed space for a Hyperloop transport capsule with reference to reducing the energy demand of a transport system. E3S Web Conf. 2019, 108, 01032. [CrossRef]

59. Sayeed, J.; Abdelrahman, A.S.; Youssef, M.Z. Hyperloop Transportation System: Control, and Drive System Design. In Proceedings of the 2018 IEEE Energy Conversion Congress and Exposition (ECCE), Portland, OR, USA, 23-27 September 2018; pp. 2767-2773.

60. Dudnikov, E.E. The Problem of Ensuring the Tightness in Hyperloop Passenger Systems. In Proceedings of the Eleventh International Conference "Management of Large-Scale System Development" (MLSD), Moscow, Russia, 1-3 October 2018; pp. 1-4. [CrossRef]

61. Ji, W.-Y.; Jeong, G.; Park, C.-B.; Jo, I.-H.; Lee, H.-W. A study of non symmetric double-sided linear induction motor for Hyperloop All-In-One System (propulsion, levitation, and guidance). IEEE Trans. Magn. 2018, 54, 2848292. [CrossRef]

62. Abdelrahman, A.S.; Sayeed, J.; Youssef, M.Z. Hyperloop Transportation System: Analysis, Design, Control, and Implementation. IEEE Trans. Ind. Electron. 2018, 65, 7427-7436. [CrossRef]

63. Goeverden, K.V.; Milakis, D.; Janic, M.M.; Konings, R. Analysis and modelling of performances of the HL (Hyperloop) transport system. Eur. Transp. Res. Rev. 2018, 10, 41. [CrossRef]

64. Opgenoord, M.M.J.; Caplan, P.C. Aerodynamic Design of the Hyperloop Concept. AIAA J. 2018, 56, 4261-4270. [CrossRef]

65. Kang, H.; Jin, Y.; Kwon, H.; Kim, K. A Study on the Aerodynamic Drag of Transonic Vehicle in Evacuated Tube Using Computational Fluid Dynamics. Int. J. Aeronaut. Space 2017, 18, 614-622. [CrossRef]

66. Heaton, T.H. Inertial Forces from Earthquakes on a Hyperloop Pod. Bull. Seismol. Soc. Am. 2017, 107, 2521-2524. [CrossRef]

67. Braun, J.; Sousa, J.; Pekardan, C. Aerodynamic Design and Analysis of the Hyperloop. AIAA J. 2017, 55, 4053-4060. [CrossRef]

68. Janzen, R. TransPod Ultra-High-Speed Tube Transportation: Dynamics of Vehicles and Infrastructure. Procedia Eng. 2017, 199, 8-17. [CrossRef]

69. Espacenet. 2020. Available online: https://worldwide.espacenet.com (accessed on 25 July 2020).

70. Meyer, M.; Siniläinen, T.; Utecht, J.T. Towards hybrid triple helix indicators: A study of university-related patents and a survey of academic inventors. Scientometrics 2003, 58, 321-350. [CrossRef]

71. Hogan, T.; Zhou, Q. Defining university spin-offs. In New Technology Based Firms in the New Millennium; Emerald Group Publishing Limited: Bingley, UK, 2010; Volume 8, pp. 7-23.

72. EIT. 2020. Available online: https://eit.europa.eu/news-events/news/test-centre-netherlands (accessed on 25 July 2020).

73. Zeleros. 2020. Available online: https://zeleros.com/ (accessed on 25 July 2020).

74. Hyperloop Transportation Technologies. 2020. Available online: https://www.hyperlooptt.com/ (accessed on 25 July 2020).

75. European Commission. 2020. Available online: https://ec.europa.eu/eipp (accessed on 25 July 2020).

76. Businesswire. Hyperloop Transportation Technologies and TÜV SÜD Announce Publication of Industry First Complete Safety Guidelines. 2020. Available online: https://www.businesswire.com/news/ home/20200714005275/en/Hyperloop-Transportation-Technologies-T\%C3\%9CV-S\%C3\%9CD-AnnouncePublication (accessed on 25 July 2020).

77. European Commission. STRIA Roadmap on Connected and Automated Transport-Road, Rail and Waterborne; European Commission: Brussels, Belgium, 2019.

78. European Commission. H2020-S2R-OC-IPX-01-2020: Innovation in Guided Transport. Available online: https://ec.europa.eu/info/funding-tenders/opportunities/portal/screen/opportunities/topic-details/s2r-ocipx-01-2020 (accessed on 25 July 2020). 
79. CEN-CENELEC. A Newcomer in the European Transport Standardization Family: JTC 20 on Hyperloop Systems. 2020. Available online: https://www.cencenelec.eu/news/articles/Pages/AR-2020-003.aspx (accessed on 25 July 2020).

80. US DOT. NETT Council. 2019. Available online: https://www.transportation.gov/nettcouncil (accessed on 25 July 2020). 